\title{
Study on the Permeability Evolution Model of Mining- Disturbed Coal
}

\author{
Hengyi Jia $\mathbb{D}^{1,2}$ and Delong Zou $^{3}$ \\ ${ }^{1}$ China Coal Research Institute, Beijing 100013, China \\ ${ }^{2}$ State Key Lab of Coal Resources High Efficient Mining and Clean Utilization, Beijing 100013, China \\ ${ }^{3}$ Shenyang Research Institute of CCTEG, Shenyang 113122, China
}

Correspondence should be addressed to Hengyi Jia; jiahengyi2@163.com

Received 29 June 2021; Revised 29 July 2021; Accepted 13 August 2021; Published 26 August 2021

Academic Editor: Feng Du

Copyright (C) 2021 Hengyi Jia and Delong Zou. This is an open access article distributed under the Creative Commons Attribution License, which permits unrestricted use, distribution, and reproduction in any medium, provided the original work is properly cited.

\begin{abstract}
Coal permeability plays an important role in the simultaneous exploitation of coal and coal-bed methane (CBM). The stress of mining-disturbed coal changes significantly during coal mining activities, causing damage and destruction of the coal mass, ultimately resulting in a sharp increase in permeability. Conventional triaxial compression and permeability tests were conducted on a triaxial creep-seepage-adsorption and desorption experimental device to investigate the permeability evolution of mining-disturbed coal. The permeability evolution models considering the influence of the stress state and stress path on the fracture propagation characteristics were established based on the permeability difference in the deformation stages of the coal mass. The stress-strain curve of the coal was divided into an elastic stage, yield stage, and plastic flow stage. As the axial stress increased, the permeability decreased and then increased, and the curve's inflection point corresponded to the yield point. The permeability models exhibited a good agreement with the experimental data and accurately reflected the overall trends of the test results. The results of this study provide a theoretical basis for coal mine disaster prevention and the simultaneous exploitation of coal and CBM.
\end{abstract}

\section{Introduction}

Coal-bed methane that is also called gas is an unconventional natural gas generated during coalification and accumulates in coal seams. Although CBM is a clean and efficient energy source, it is also a disaster factor and greenhouse gas in coal mining. The exploitation of CBM can reduce the occurrence of coal mine accidents and greenhouse gas emissions and minimize energy shortages. The permeability of coal seams is the decisive parameter affecting CBM exploitation. In China, coal seams are characterized by high in situ stress, strong adsorption features, and low permeability, making the extraction of CBM relatively difficult $[1,2]$. Therefore, improving the permeability of coal seams is crucial for the efficient extraction of CBM. When coal seams are mined, the stress of mining-disturbed coal undergoes complex changes, resulting in the deformation, damage, and permeability enhancement of the coal. Therefore, the simultaneous exploitation of coal and CBM has been widely promoted and applied in China.

Permeability models of coal are the basis for planning gas drainage boreholes and improving gas drainage efficiency. Scholars conducted numerous studies on coal seam permeability models. Shi and Durucan [3] presented a permeability model that considered gas desorption in linear elastic coal-beds under uniaxial strain conditions. Liu et al. [4] established a dual-porosity model considering coal deformation caused by gas adsorption. Connel et al. [5] established a permeability model of coal for triaxial stress and gas adsorption conditions based on the porous elastic theory. Perera et al. [6] derived a triaxial stress coal permeability model based on the theory of elasticity with the gas injection pressure, confining stress, axial load, and gas adsorption as control variables. Lu et al. [7] calculated porosity changes 
from the perspective of coal matrix-fracture interactions and established permeability models with different mechanical boundaries under the joint action of effective stress and adsorption deformation. The above permeability models do not consider the effect of coal damage and destruction on permeability. In coal mining activities, the stress of the mining-disturbed coal changes significantly, causing damage and destruction of the coal mass, ultimately resulting in a sharp increase in permeability. Therefore, it is urgent to study the permeability evolution model of miningdisturbed coal.

Scholars have focused on the effect of damage and destruction on coal permeability in recent years. Xie et al. [8] considered the damage caused by the shrinkage of the coal matrix after gas drainage and established a coal permeability model to describe the spatial and temporal distribution of coal permeability within the effective influence zone of the borehole. Zhang et al. [9] established a damage variable that is directly related to the effective strain and developed a dynamic model of the permeability evolution using a scalar damage variable. Xue et al. [10] considered the influence of excavation damage on coal permeability and established a postpeak permeability model based on the parallel plate model. The stress path experienced by the coal mass determines the propagation characteristics of the fractures, determining the change law of permeability. On the other hand, the initial stress state also significantly influences fracture propagation and permeability. However, few studies investigated the influence of the initial stress state and stress path on the propagation characteristics of fractures and permeability changes.

In this study, mechanical and seepage experiments of coal were conducted to obtain the evolution law of permeability with the strain. The permeability models considering the influence of the initial stress state and stress path on the fracture propagation characteristics were established and verified by experimental data. The results of this study provide a theoretical basis for coal mine disaster prevention and the simultaneous exploitation of coal and CBM.

\section{Experimental Study on Permeability Evolution of Mining-Disturbed Coal}

2.1. Specimens. The coal used in the test was collected from the No. 2 coal seam of the Zhongxing coal mine. The coal deposits are broken and have low strength because of tectonic stress, making it difficult to obtain a raw coal specimen. Studies have shown that although reconstituted coal specimens have larger deformation and permeability than raw coal specimens, their deformation characteristics and permeability evolution are similar [11]. Therefore, reconstituted coal specimens were used in the test.

Coal particles sieved through a 40-60 mesh were mixed with a small amount of water and packed into a mold. A pressure of $200 \mathrm{kN}$ was applied to the mold for $1 \mathrm{~h}$, and specimens with a diameter of $50 \mathrm{~mm}$ and a height of $100 \mathrm{~mm}$ were obtained. The specimens were placed in a $60^{\circ} \mathrm{C}$ vacuum oven for $48 \mathrm{~h}$ and wrapped with fresh film after cooling for the subsequent analysis.
2.2. Experimental Method. Conventional triaxial compression and permeability tests were conducted on the triaxial creep-seepage-adsorption and desorption experimental device. The device consisted of a servo loading system, adsorption-desorption-seepage system, gas pressure control system, temperature control system, and deformation measurement system.

The steady-state method was adopted to measure the permeability of the specimens. The permeability was calculated as follows:

$$
\mathrm{k}=\frac{2 \mu \mathrm{P}_{0} L Q}{A\left(P_{1}^{2}-P_{0}^{2}\right)}
$$

where $\mathrm{k}$ is the permeability $\left(\mathrm{m}^{2}\right), \mu$ is the gas kinematic viscosity, $P_{0}$ is the gas pressure at the outlet of the specimens $(0.1 \mathrm{MPa}), L$ is the length of the specimens $(\mathrm{m}), Q$ is the gas permeation rate $\left(\mathrm{m}^{3} / \mathrm{s}\right), A$ is the cross-sectional area of the specimens $\left(\mathrm{m}^{2}\right)$, and $P_{1}$ is the gas pressure at the inlet of the specimens $(\mathrm{MPa})$.

Three specimens were selected, and the axial stress and confining stress were applied at the same speed to the hydrostatic pressure state of 2,4 , and $8 \mathrm{MPa}$, respectively. Subsequently, the confining stress remained unchanged, and the axial stress was applied at the speed of $100 \mathrm{~N} / \mathrm{s}$ until the specimens failed. During the test, the deformation and gas seepage characteristics were recorded. For the convenience of analysis, the unit of permeability $\left(\mathrm{m}^{2}\right)$ was converted to millidarcy; their relationship is $1 \mathrm{~m}^{2}=10^{15} \mathrm{mD}$.

2.3. Results and Analysis. Figure 1 shows the relationship between the stress-strain curve and permeability-strain curve. The stress-strain curve can be divided into the elastic stage, yield stage, and plastic flow stage. After the yield stage, the strain exhibits the characteristics of plastic flow, and the specimens show no apparent signs of failure. The experiments were stopped after the specimens showed plastic flow characteristics to prevent the strain from exceeding the measurement range and damaging the strain sensor. In Figure 1, the \# 1 coal specimen is used as an example, and the points $A$ , $B, C$, and $D$ represent the starting point of loading, the expansion point, the yield point, and the end of the test, respectively. In the initial stage, the volume of the specimen is compressed continuously, and the volumetric strain increases gradually. From point $B$, the specimen expands, and the volumetric strain decreases. As the axial stress increases, the permeability decreases and then increases, and the curve's inflection point corresponds to point $C$.

During the deformation, the permeability depends on the effective porosity. There are few new fractures in the $A$ $-B$ stage, and the primary fractures are elastically compacted under the increasing axial stress. In this stage, the specimen is in an elastic deformation state, and the permeability decreases with the volume compression. From point $B$, the volume expands, and the permeability continues to decline. Tensile microfractures are gradually formed in the coal parallel to the direction of the axial stress, causing volume expansion. However, these microfractures are not connected, and the effective porosity does not increase. At the 


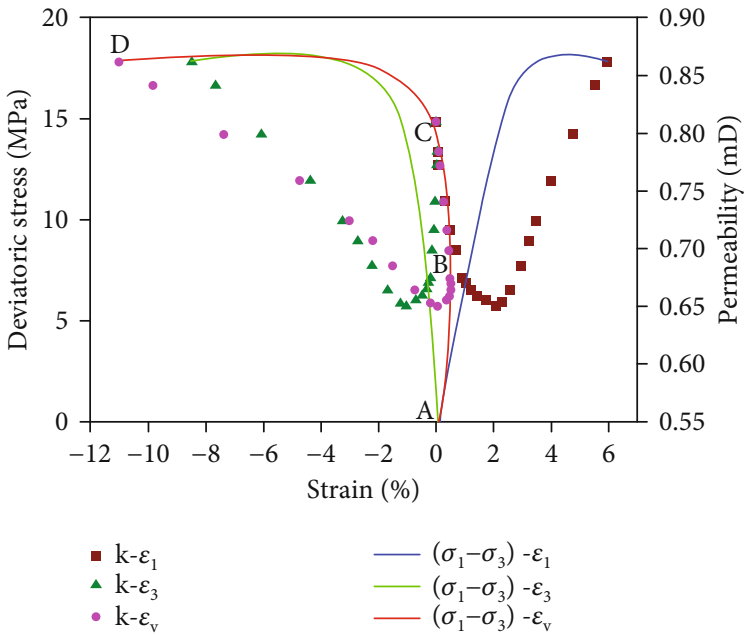

(a) \#1 coal specimen

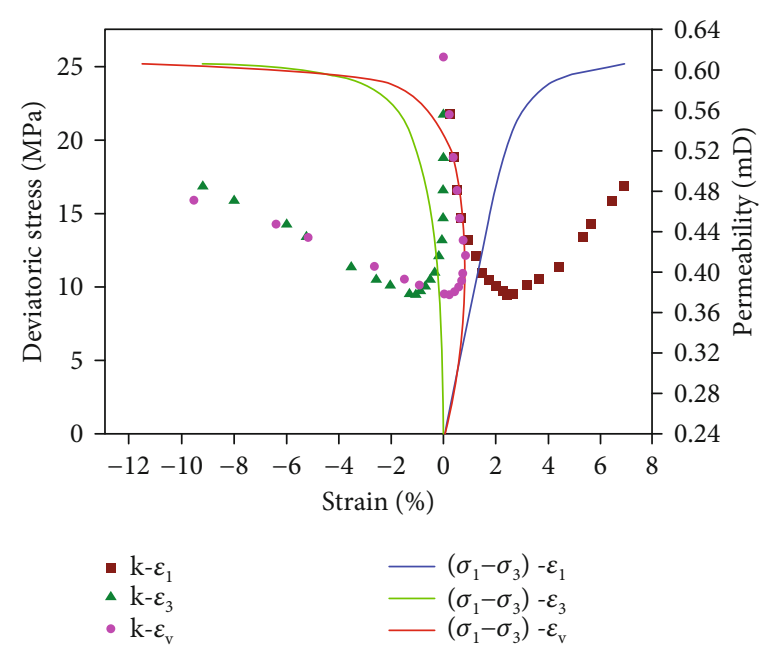

(b) \#2 coal specimen

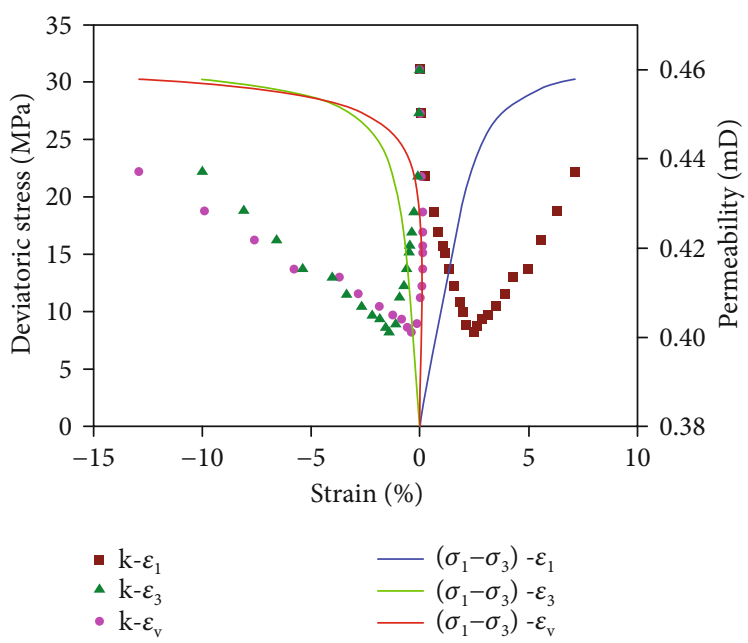

(c) \#3 coal specimen

Figure 1: The curve of permeability-strain and stress-strain of coal specimens.

same time, the increasing axial stress causes the closure of the primary fractures. Therefore, even if the volume expands, the permeability continues to decrease. From point $C$, the connectivity of the new fractures increases, and the permeability increases with the volume expansion.

Figure 2 shows the failure characteristics of the coal specimens after the experiments. The three specimens all suffered shear failure, and the angle between the failure crack and the axial direction increases with an increase in the confining pressure. Specimens \#2 and \#3 also showed tensile failure, which was likely caused by the mechanical properties of the specimens and the limitations of the equipment performance.

\section{Permeability Model of Mining- Disturbed Coal}

3.1. Permeability Model in the Elastic Stage. The pores in which the fluid can flow are called effective pores, whereas the other pores are called invalid pores. Effective and invalid pores exist in both raw coal and reconstituted coal under certain stress conditions, and only the effective pores affect the permeability.

The permeability of coal can be expressed using the Kozeny-Carman equation as follows:

$$
k=\frac{\phi^{\prime 3}}{C S^{2}\left(1-\phi^{\prime}\right)^{2}}
$$

where $k$ is the permeability $\left(\mathrm{m}^{2}\right), \phi^{\prime}$ is the effective porosity, $S$ is the surface area of the pores per unit volume of coal, and $C$ is a coefficient related to the tortuosity of the coal fractures.

When the coal undergoes elastic deformation due to external stress, only the opening and shape of the fractures change. Thus, the parameter $S$ can be regarded as a constant. Equation (1) can be rewritten as follows:

$$
\frac{k}{k_{0}}=\frac{C_{0}}{C}\left(\frac{\phi^{\prime}}{\phi_{0}^{\prime}}\right)^{3}\left(\frac{1-\phi_{0}^{\prime}}{1-\phi^{\prime}}\right)^{2}=\alpha\left(\frac{\phi^{\prime}}{\phi_{0}^{\prime}}\right)^{3}\left(\frac{1-\phi_{0}^{\prime}}{1-\phi^{\prime}}\right)^{2},
$$




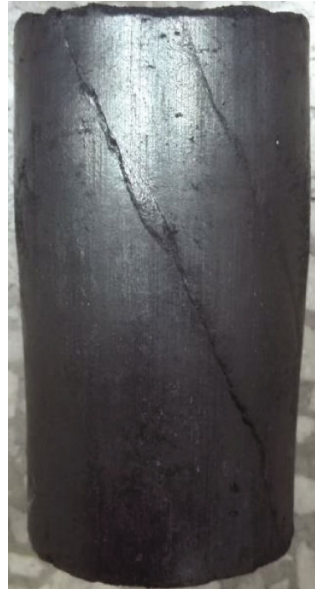

(a) \#1 coal specimen

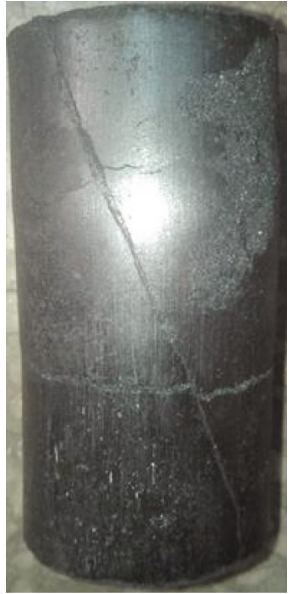

(b) \#2 coal specimen

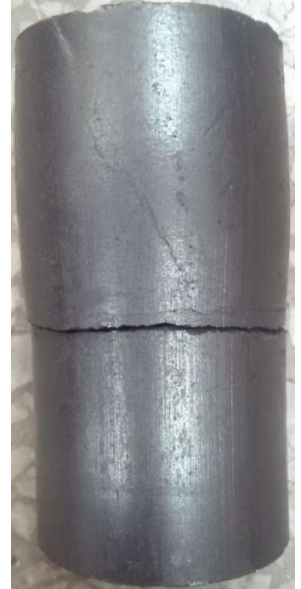

(c) \#3 coal specimen

FIgURE 2: Failure characteristics of coal specimens.

where $C_{0}, k_{0}$, and $\phi_{0}^{\prime}$ and $C, k$, and $\phi^{\prime}$ are the coefficient, the permeability, and the effective porosity before and after coal mass deformation, respectively, $\left(\alpha=C_{0} / C\right)$.

The total porosity of coal can be expressed by the following equation:

$$
\begin{aligned}
\phi & =\frac{V_{\mathrm{p} 0}+\Delta V_{p}}{V_{b 0}+\Delta V_{b}}=1-\frac{V_{s 0}+\Delta V_{s}}{V_{b 0}+\Delta V_{b}}=1-\frac{V_{s 0}\left(1+\Delta V_{s} / V_{s 0}\right)}{V_{b 0}\left(1+\Delta V_{b} / V_{b 0}\right)} \\
& =1-\frac{\left(1-\phi_{0}\right)}{1+\varepsilon_{\mathrm{V}}}\left(1+\frac{\Delta V_{s}}{V_{s 0}}\right),
\end{aligned}
$$

where $\phi_{0}$ and $\phi$ are the total porosity before and after deformation, respectively; $V_{\mathrm{p} 0}, V_{\mathrm{b} 0}$, and $V_{\mathrm{s} 0}$ are the initial pore volume, coal mass volume, and solid skeleton volume of the coal, respectively; $\Delta V_{\mathrm{p}}, \Delta V_{\mathrm{b}}$, and $\Delta V_{\mathrm{s}}$ are the increment of the pore volume, coal mass volume, and solid skeleton volume, respectively; and $\varepsilon_{\mathrm{V}}$ is the volumetric strain.

If $\Delta V_{s}=0$, i.e., regardless of changes in the volume of the skeleton, then

$$
\phi=\frac{\phi_{0}+\varepsilon_{\mathrm{V}}}{1+\varepsilon_{\mathrm{V}}} .
$$

The volumetric strain in Equation (5) is solely caused by pores in coal.

Only a change in the effective pores will affect the permeability during the coal mass deformation. Here, a coefficient $\lambda_{1}$ is introduced to represent the ratio of the volumetric strain caused by the effective pores to the total volumetric strain in this stage $\left(\varepsilon_{\mathrm{V} \text {-effective }} / \varepsilon_{\mathrm{V}}=\lambda_{1}, 0 \leq \lambda_{1} \leq 1\right)$. According to Equation (5), the effective porosity of coal after deformation is

$$
\phi^{\prime}=\frac{\phi_{0}^{\prime}+\varepsilon_{\mathrm{V} \text {-effective }}}{1+\varepsilon_{\mathrm{V}}}=\frac{\phi_{0}^{\prime}+\lambda_{1} \varepsilon_{\mathrm{V}}}{1+\varepsilon_{\mathrm{V}}},
$$

where $\varepsilon_{\mathrm{V} \text {-effective }}$ is the volumetric strain caused by the effective pores.
By substituting Equation (6) into Equation (3), we obtain

$$
\frac{\mathrm{k}}{\mathrm{k}_{0}}=\frac{\alpha}{1+\varepsilon_{\mathrm{V}}}\left(1+\frac{\lambda_{1} \varepsilon_{\mathrm{V}}}{\phi_{0}^{\prime}}\right)^{3}\left(\frac{1-\phi_{0}^{\prime}}{1+\varepsilon_{\mathrm{V}}-\phi_{0}^{\prime}-\lambda_{1} \varepsilon_{\mathrm{V}}}\right)^{2} .
$$

Because the initial stress state and stress path affect the propagation characteristics of the fractures, Equation (7) reflects the influence of the initial stress state and stress path on the fracture propagation characteristics and permeability of the coal mass.

3.2. Permeability Model in the Damage Stage. When the coal mass is damaged, the primary fractures expand, and new fractures are created. Thus, the parameter $S$ in Equation (1) is no longer a constant, and the equation can be rewritten as follows:

$$
k=\frac{\phi^{\prime 3}}{C S^{2}\left(1-\phi^{\prime}\right)^{2}}=\frac{\phi^{\prime 3}}{C\left(A_{s} / V_{b}\right)^{2}\left(1-\phi^{\prime}\right)^{2}},
$$

where $A_{s}$ is the total surface area of the pores in the coal mass, and $V_{b}$ is the coal mass volume.

Then, the initial permeability becomes

$$
k_{0}=\frac{\phi_{0}^{\prime 3}}{C_{0}\left(A_{s 0} / V_{b 0}\right)^{2}\left(1-\phi_{0}^{\prime}\right)^{2}} .
$$

When the coal mass is damaged, the surface area of the pores changes:

$$
A_{s}=A_{s 0}(1+\psi)
$$

The permeability becomes

$$
\mathrm{k}=\frac{\phi^{\prime 3}}{C\left(\left(A_{s 0}(1+\psi)\right) /\left(V_{b 0}\left(1+\varepsilon_{\mathrm{V}}\right)\right)\right)^{2}\left(1-\phi^{\prime}\right)^{2}} .
$$


We obtain

$$
\frac{k}{k_{0}}=\alpha\left(\frac{\phi^{\prime}}{\phi_{0}^{\prime}}\right)^{3}\left(\frac{1-\phi_{0}^{\prime}}{1-\phi^{\prime}}\right)^{2}\left(\frac{1+\varepsilon_{\mathrm{V}}}{1+\psi}\right)^{2}
$$

We assume that the change in the pore surface area can be ignored; thus, Equation (12) can be simplified as

$$
\frac{k}{k_{0}}=\alpha\left(\frac{\phi^{\prime}}{\phi_{0}^{\prime}}\right)^{3}\left(\frac{1-\phi_{0}^{\prime}}{1-\phi^{\prime}}\right)^{2}\left(1+\varepsilon_{\mathrm{V}}\right)^{2}
$$

As shown in Figure 1, point $B$ is the starting point of the expansion and damage. For the $B-C$ stage, Equation (13) should be rewritten as

$$
\frac{k}{k_{\text {expansion }}}=\alpha\left(\frac{\phi^{\prime}}{\phi_{\text {expansion }}^{\prime}}\right)^{3}\left(\frac{1-\phi_{\text {expansion }}^{\prime}}{1-\phi^{\prime}}\right)^{2}\left(1+\varepsilon_{V}-\varepsilon_{\mathrm{V} \text {-expansion }}\right)^{2} \text {, }
$$

where $k_{\text {expansion }}, \phi_{\text {expansion, }}^{\prime}$ and $\varepsilon_{\mathrm{V} \text {-expansion }}$ are the permeability, effective porosity, and volumetric strain at the starting point of the expansion, respectively, and $k, \phi^{\prime}$, and $\varepsilon_{\mathrm{V}}$ are the permeability, effective porosity, and volumetric strain in the $B-C$ stage, respectively.
The coal specimen is being damaged from point $B$, and the volume continues to expand. However, the effective porosity has not increased because the tensile microfractures generated in this stage are not connected. In addition, as the axial stress increases, the primary fractures continue to close, resulting in a decrease in permeability. The coefficient $\lambda_{2}$ is introduced to express the ratio of the volumetric strain caused by the effective pores to the total volumetric strain in this stage, i.e., $\varepsilon_{\mathrm{V} \text {-effective }} /\left(\varepsilon_{\mathrm{V}}-\varepsilon_{\mathrm{V} \text {-expansion }}\right)=\lambda_{2}$. The trend of the volumetric strain caused by the effective pores is opposite to that of the total volumetric strain; thus, $-1 \leq \lambda_{2} \leq 0$.

According to Equation (5), the effective porosity in $B-C$ stage can be obtained as

$$
\phi^{\prime}=\frac{\phi_{\text {expansion }}^{\prime}+\lambda_{2}\left(\varepsilon_{V^{-}} \varepsilon_{\mathrm{V} \text {-expansion }}\right)}{1+\varepsilon_{\mathrm{V}}-\varepsilon_{\mathrm{V} \text {-expansion }}} .
$$

According to Equation (6), we obtain

$$
\phi_{\text {expansion }}^{\prime}=\frac{\phi_{0}^{\prime}+\lambda_{1} \varepsilon_{\mathrm{V} \text {-expansion }}}{1+\varepsilon_{\mathrm{V} \text {-expansion }}} .
$$

By substituting Equations (15) and (16) into Equation (14), we derive

$$
\begin{aligned}
\mathrm{k}= & \mathrm{k}_{\text {expansion }} \alpha\left(1+\varepsilon_{\mathrm{V}}-\varepsilon_{\mathrm{V} \text {-expansion }}\right)\left[1+\frac{\lambda_{2}\left(1+\varepsilon_{\mathrm{V} \text {-expansion }}\right)\left(\varepsilon_{\mathrm{V}}-\varepsilon_{\mathrm{V} \text {-expansion }}\right)}{\phi_{0}^{\prime}+\lambda_{1} \varepsilon_{\mathrm{V} \text {-expansion }}}\right]^{3} \\
& \times\left\{\frac{1+\varepsilon_{\mathrm{V} \text {-expansion }}-\phi_{0}^{\prime}-\lambda_{1} \varepsilon_{\mathrm{V} \text {-expansion }}}{\left[\left(1-\lambda_{2}\right)\left(\varepsilon_{\mathrm{V}}-\varepsilon_{\mathrm{V} \text {-expansion }}\right)+1\right]\left(1+\varepsilon_{\mathrm{V} \text {-expansion }}\right)-\phi_{0}^{\prime}-\lambda_{1} \varepsilon_{\mathrm{V} \text {-expansion }}}\right\}^{2} .
\end{aligned}
$$

Equation (17) is the theoretical model of permeability in the $B-C$ stage.

If the yield point is the initial condition, Equation (13) should be rewritten as

$$
\frac{k}{k_{\text {yield }}}=\alpha\left(\frac{\phi^{\prime}}{\phi_{\text {yield }}^{\prime}}\right)^{3}\left(\frac{1-\phi_{\text {yield }}^{\prime}}{1-\phi^{\prime}}\right)^{2}\left(1+\varepsilon_{\mathrm{V}}-\varepsilon_{\mathrm{V} \text {-yield }}\right)^{2} \text {, }
$$

where $k_{\text {yield }}, \phi_{\text {yield }}^{\prime}$, and $\varepsilon_{\mathrm{V} \text {-yield }}$ and $k, \phi^{\prime}$, and $\varepsilon_{\mathrm{V}}$ are the permeability, effective porosity, and volumetric strain of the coal at the yield point and in the $C-D$ stage, respectively.

The permeability increases from point $C$ because of the increasing of effective porosity. The coefficient $\lambda_{3}$ is introduced to express the ratio of the volumetric strain caused by the effective pores to the total volumetric strain at this stage $\left(\varepsilon_{\mathrm{V} \text {-effective }} /\left(\varepsilon_{\mathrm{V}}-\varepsilon_{\mathrm{V} \text {-yield }}\right)=\lambda_{3}, 0 \leq \lambda_{3} \leq 1\right)$.
According to Equation (5), the effective porosity in the $C$ $-D$ stage can be obtained:

$$
\phi^{\prime}=\frac{\phi_{\text {yield }}^{\prime}+\lambda_{3}\left(\varepsilon_{\mathrm{V}}-\varepsilon_{\mathrm{V} \text {-yield }}\right)}{1+\varepsilon_{\mathrm{V}}-\varepsilon_{\mathrm{V} \text {-yield }}}
$$

According to Equation (15), we obtain

$$
\phi_{\text {yield }}^{\prime}=\frac{\phi_{\text {expansion }}^{\prime}+\lambda_{2}\left(\varepsilon_{\mathrm{V} \text {-yield }}-\varepsilon_{\mathrm{V} \text {-expansion }}\right)}{1+\varepsilon_{\mathrm{V} \text {-yield }}-\varepsilon_{\mathrm{V} \text {-expansion }}} .
$$

By substituting Equations (16), (19), and (20) into Equation (18), we obtain 


$$
\begin{aligned}
\mathrm{k}= & \mathrm{k}_{\mathrm{yield}} \alpha\left(1+\varepsilon_{\mathrm{V}}-\varepsilon_{\mathrm{V} \text {-yield }}\right)\left[1+\frac{\lambda_{3}\left(\varepsilon_{V^{-}} \varepsilon_{\mathrm{V} \text {-yield }}\right)\left(1+\varepsilon_{\mathrm{V} \text {-yield }}-\varepsilon_{\mathrm{V} \text {-expansion }}\right)\left(1+\varepsilon_{\mathrm{V} \text {-expansion }}\right)}{\phi_{0}^{\prime}+\lambda_{1} \varepsilon_{\mathrm{V} \text {-expansion }}+\lambda_{2}\left(\varepsilon_{\mathrm{V} \text {-yield }}-\varepsilon_{\mathrm{V} \text {-expansion }}\right)\left(1+\varepsilon_{\mathrm{V} \text {-expansion }}\right)}\right]^{3} \\
& \times\left\{\frac{\left[\left(1-\lambda_{2}\right)\left(\varepsilon_{\mathrm{V} \text {-yield }}-\varepsilon_{\mathrm{V} \text {-expansion }}\right)+1\right]\left(1+\varepsilon_{\mathrm{V} \text {-expansion }}\right)-\phi_{0}^{\prime}-\lambda_{1} \varepsilon_{\mathrm{V} \text {-expansion }}}{\left[\left(1-\lambda_{2}\right)\left(\varepsilon_{\mathrm{V} \text {-yield }}-\varepsilon_{\mathrm{V} \text {-expansion }}\right)+1+\left(1+\varepsilon_{\mathrm{V} \text {-yield }}-\varepsilon_{\mathrm{V} \text {-expansion }}\right)\left(1-\lambda_{3}\right)\left(\varepsilon_{\mathrm{V}}-\varepsilon_{\mathrm{V} \text {-yield }}\right)\right]\left(1+\varepsilon_{\mathrm{V} \text {-expansion }}\right)-\phi_{0}^{\prime}-\lambda_{1} \varepsilon_{\mathrm{V} \text {-expansion }}}\right\}^{2} .
\end{aligned}
$$

Equation (21) is the theoretical model of permeability in the $C$-D stage. Equations (17) and (21) also reflect the influence of the initial stress and stress path on the fracture propagation characteristics and permeability of the coal mass.

3.3. Verification of the Permeability Model. In the previous section, the permeability evolution models in different deformation stages were obtained through theoretical derivation. Subsequently, the results of conventional triaxial compression and permeability tests were used to verify the permeability models. The initial effective porosity of the specimens was determined first. According to the test protocol $[12,13]$, the effective porosity of the specimens with different confining stress values was measured using the triaxial creep-seepage-adsorption and desorption experimental device. The effective porosities are 0.08, 0.06 , and 0.043 when the confining stress values are $2 \mathrm{MPa}, 4 \mathrm{MPa}$, and $8 \mathrm{MPa}$, respectively. As the confining stress increases, the effective porosity decreases. In the permeability experiment, it is stipulated that $\varepsilon_{\mathrm{V}}$ is a positive value when the specimen is compressed and a negative value when it is expanded, which is opposite to the stipulation in the permeability models. Therefore, negative signs were added to the volumetric strains in the permeability models. We used Equation (7) to fit the test data of the $A-B$ stage, Equation (17) to fit the test data of the $B-C$ stage, and Equation (21) to fit the test data of the $C-D$ stage. When fitting the test data with Equation (17), the value of $\lambda_{1}$ is the fitting result of Equation (7). Similarly, when Equation (21) is used to fit the test data, the values of $\lambda_{1}$ and $\lambda_{2}$ are the fitting results of Equations (7) and (17), respectively.

Figures 3-5 show the fitting results of the permeability, and Table 1 lists the results of the parameters. It can be seen that the permeability models of the $A-B$ stage and the $C-D$ stage fit the permeability data well. The parameters $\lambda_{1}$ and $\lambda_{3}$ decrease with an increase in confining stress, indicating that the ratio of the volumetric strain caused by the effective pores to the total volumetric strain decreases with an increase in the confining stress, and the sensitivity of the permeability to the volumetric strain decreases. The fitting results of the $B-C$ stage are slightly worse, and the change law of $\lambda_{2}$ with confining stress is not obvious. However, the overall trends of the permeability model and the test data are the same.

\section{Discussion}

The stress state of mining-disturbed coal is changed by mining activities, causing elastic deformation and even damage and changing the coal permeability [14-16]. The results of the experiments show that the effective porosity of the coal decreases with the increasing axial stress during the elastic deformation stage, resulting in a decrease in permeability. Tensile microfractures begin to form in the coal from point $B$, and the coal begins to expand. However, the tensile microfractures are not connected, and the effective porosity does not increase. At the same time, the original pores decrease with the increasing axial stress. Therefore, although the coal continues to expand, the permeability is still decreasing in the $B-C$ stage. From point $C$, the tensile microfractures are connected, and the effective porosity increases. The permeability increases with the expanding coal volume. Therefore, the evolution law of permeability is closely related to the propagation characteristics of the coal fractures.

Establishing a suitable permeability model of miningdisturbed coal is crucial for understanding the fluid seepage mechanism in coal $[17,18]$. Most existing permeability models are based on CBM exploitation and ignore the influence of damage on permeability. Xie et al. [19] considered the volumetric change of damage coal with cracks induced by coupling of the abutment pressure under different mining conditions, pore pressure, and expansion caused by gas adsorption and proposed a new word of mining-enhanced permeability meaning the change in permeability by volumetric change of coal. Cheng et al. [20] put forward a new model with strain as a variable for unloading fractured coal by considering the effective stress and gas adsorption/desorption deformation effects. Although these studies have laid a foundation for describing the permeability evolution law of mining-disturbed coal, they all ignored the influence of the pore type on permeability. The permeability models established in this paper consider the influence of the effective and invalid pores on permeability. The initial stress state and stress path affect the propagation characteristics of coal fractures $[21,22]$. Therefore, the proposed models accurately reflect the influence of the initial stress state and stress path on permeability.

The permeability distribution law of mining-disturbed coal is the basis for achieving the simultaneous exploitation of coal and CBM. The initial stress affects the evolution characteristics of the coal fractures, which, in turn, affect 

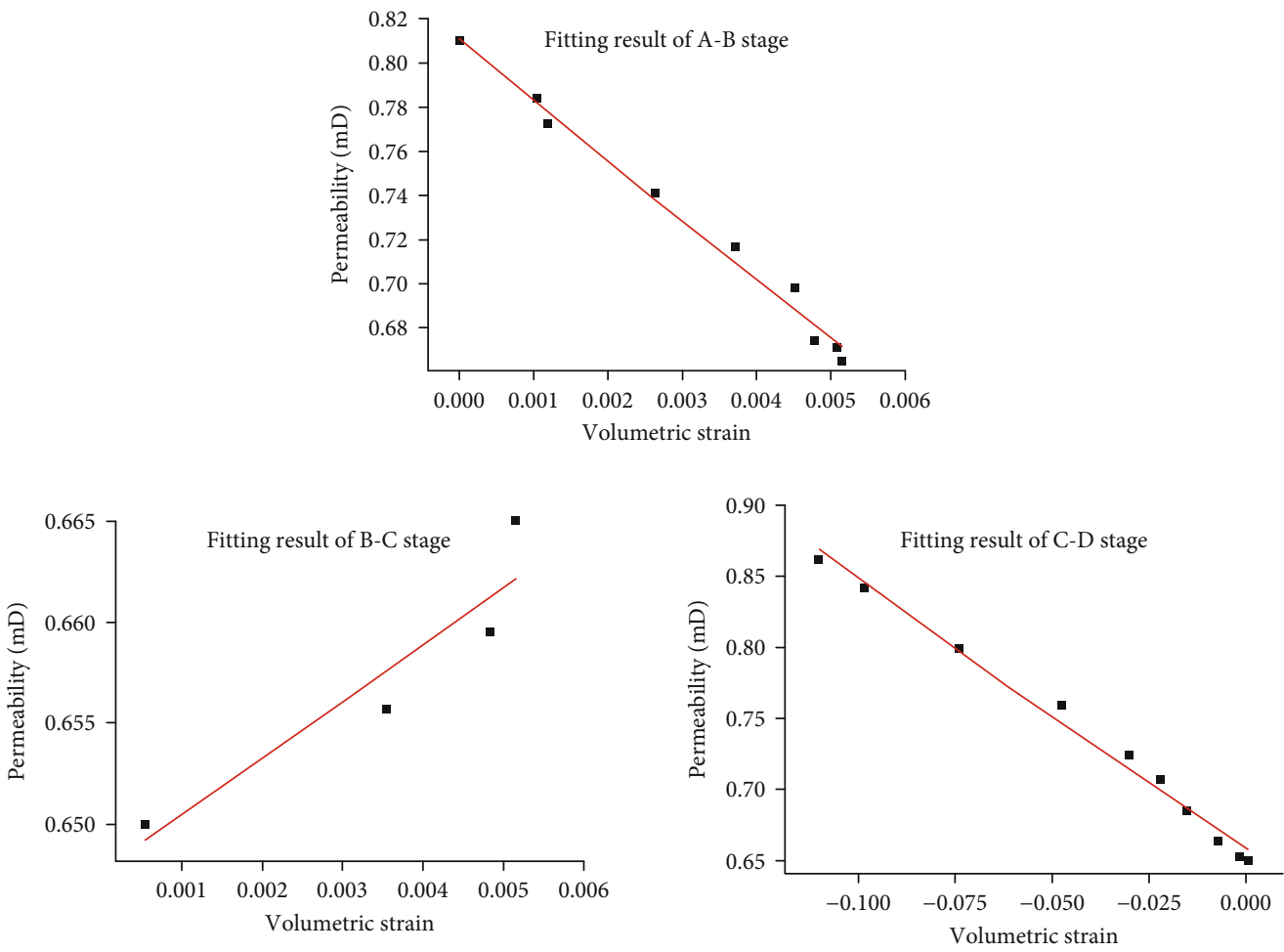

- Experimental data Fitting curve

Figure 3: Fitting results of \#1 coal specimen.
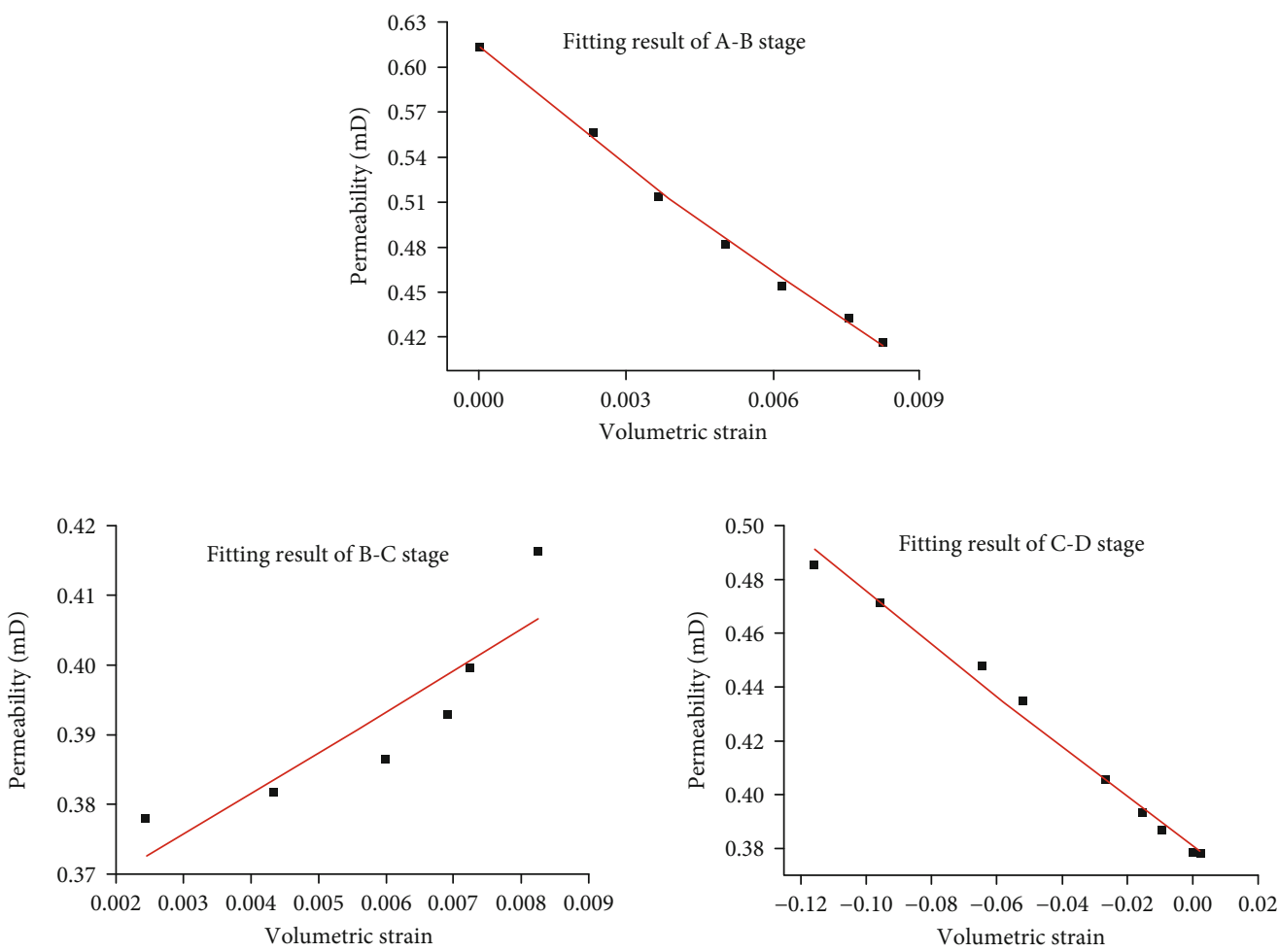

- Experimental data Fitting curve

FIGURE 4: Fitting results of \#2 coal specimen. 

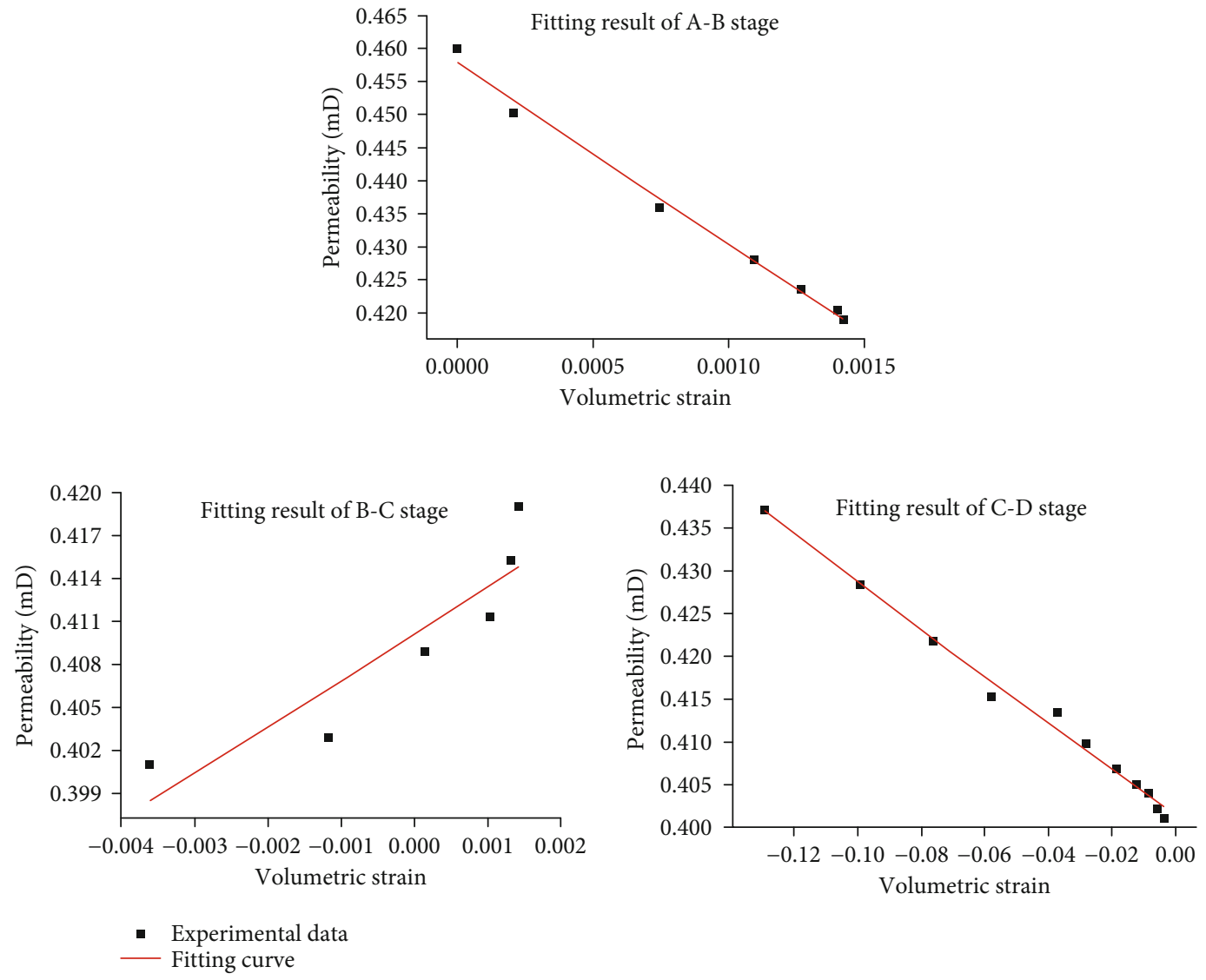

FIGURE 5: Fitting results of \#3 coal specimen.

TABLE 1: Fitting results of the parameters.

\begin{tabular}{lccccccccc}
\hline \multirow{2}{*}{ Specimen } & \multicolumn{3}{c}{$A-B$ stage } & \multicolumn{3}{c}{$B$ - $C$ stage } & \multicolumn{2}{c}{$C$ - $D$ stage } \\
& $\alpha$ & $\lambda_{1}$ & $R^{2}$ & $\alpha$ & $\lambda_{2}$ & $R^{2}$ & $\alpha$ & $R_{3}$ \\
\hline$\# 1$ & 1.0019 & 0.9748 & 0.9848 & 0.9957 & -0.0745 & 0.8076 & 1.0117 & 0.0912 & 0.9866 \\
$\# 2$ & 0.9996 & 0.9142 & 0.9959 & 0.9769 & -0.2348 & 0.7424 & 1.0026 & 0.038 & 0.9883 \\
$\# 3$ & 0.9954 & 0.8948 & 0.9916 & 0.99 & -0.0923 & 0.7738 & 1.0035 & 0.0232 & 0.9911 \\
\hline
\end{tabular}

the permeability. The experimental results indicate that the higher the initial confining stress, the lower the sensitivity of the permeability to the volumetric strain is, explaining the poor permeability enhancement of long-distance protected coal seams. The permeability distribution law can be obtained using the proposed permeability models with the volumetric strain of the protected coal seam, enabling the simultaneous exploitation of coal and CBM.

\section{Conclusion}

(i) The stress-strain curve of coal was divided into the elastic stage, yield stage, and plastic flow stage. As the axial stress increased, the permeability decreased and then increased, and the inflection point of the curve corresponded to the yield point

(ii) The stress state of the coal mass is changed during mining activities, causing elastic deformation and even damage. Effective and invalid pores exist in both raw coal and reconstituted coal under certain stress conditions, but only the effective pores affect the permeability

(iii) As the confining stress increased, the ratio of the volumetric strain caused by the effective pores to the total volumetric strain decreased, and the sensitivity of the permeability to the volumetric strain decreased. The initial stress state and stress path affected the propagation characteristics of the coal fractures, influencing the evolution law of permeability

\section{Data Availability}

The data used to support the findings of this study are available from the corresponding author upon request. 


\section{Conflicts of Interest}

The authors declare that they have no conflicts of interest.

\section{Acknowledgments}

This research was financially supported by the National Natural Science Foundation of China (Grant No. 51704164).

\section{References}

[1] T. Xia, F. Zhou, J. Liu, S. Hu, and Y. Liu, "A fully coupled coal deformation and compositional flow model for the control of the pre-mining coal seam gas extraction," International Journal of Rock Mechanics and Mining Sciences, vol. 72, pp. 138148, 2014.

[2] H. Wang, X. Yang, F. du et al., "Calculation of the diffusion coefficient of gas diffusion in coal: the comparison of numerical model and traditional analytical model," Journal of Petroleum Science and Engineering, vol. 205, p. 108931, 2021.

[3] J. Q. Shi and S. Durucan, "Drawdown induced changes in permeability of coalbeds: a new interpretation of the reservoir response to primary recovery," Transport in Porous Media, vol. 56, no. 1, pp. 1-16, 2004.

[4] J. Liu, Z. Chen, D. Elsworth, X. Miao, and X. Mao, "Evaluation of stress-controlled coal swelling processes," International Journal of Coal Geology, vol. 83, no. 4, pp. 446-455, 2010.

[5] L. D. Connell, M. Lu, and Z. Pan, "An analytical coal permeability model for tri-axial strain and stress conditions," International Journal of Coal Geology, vol. 84, no. 2, pp. 103-114, 2010.

[6] M. S. A. Perera, P. G. Ranjith, and S. K. Choi, "Coal cleat permeability for gas movement under triaxial, non-zero lateral strain condition: a theoretical and experimental study," Fuel, vol. 109, pp. 389-399, 2013.

[7] S. Lu, Y. Cheng, and W. Li, "Model development and analysis of the evolution of coal permeability under different boundary conditions," Journal of Natural Gas Science and Engineering, vol. 31, pp. 129-138, 2016.

[8] J. Xie, M. Gao, B. Yu, R. Zhang, and W. Jin, "Coal permeability model on the effect of gas extraction within effective influence zone," Geomechanics and Geophysics for Geo-Energy and GeoResources, vol. 1, no. 1-2, pp. 15-27, 2015.

[9] N. Zhang, X. Li, H. Cheng, and T. Teng, "A coupled damagehydro-mechanical model for gas drainage in lowpermeability coalbeds," Journal of Natural Gas Science and Engineering, vol. 35, pp. 1032-1043, 2016.

[10] Y. Xue, F. Gao, X. Liu, J. Li, M. Liang, and X. Li, “Theoretical and numerical simulation of the mining-enhanced permeability model of damaged coal seam," Geotechnical and Geological Engineering, vol. 34, no. 5, pp. 1425-1433, 2016.

[11] G. Z. Yin, D. K. Wang, D. M. Zhang, and W. Z. Wang, “Test analysis of deformation characteristics and compressive strengths of two types of coal specimens containing gas," Chinese Journal of Rock Mechanics and Engineering, vol. 28, no. 2, pp. 410-417, 2009.

[12] F. Du and K. Wang, "Unstable failure of gas-bearing coal-rock combination bodies: insights from physical experiments and numerical simulations," Process Safety and Environmental Protection, vol. 129, pp. 264-279, 2019.
[13] D. Wang, M. Peng, J. Wei, Q. Fu, and Y. Xia, "Development and application of tri-axial creep-seepage-adsorption and desorption experimental device for coal," Journal of China Coal Society, vol. 3, pp. 644-652, 2016.

[14] F. Du, K. Wang, X. Zhang, C. Xin, L. Shu, and G. Wang, "Experimental study of coal-gas outburst: insights from coalrock structure, gas pressure and adsorptivity," Natural Resources Research, vol. 29, no. 4, pp. 2481-2493, 2020.

[15] D. Y. Guo, P. F. Lv, J. C. Zhao, and C. Zhang, "Research progress on permeability improvement mechanisms and technologies of coalbed deep-hole cumulative blasting," International Journal of Coal Science and Technology, vol. 7, no. 2, pp. 329-336, 2020.

[16] K. Wang, F. Du, and G. Wang, "Investigation of gas pressure and temperature effects on the permeability and steady-state time of Chinese anthracite coal: an experimental study," Journal of Natural Gas Science and Engineering, vol. 40, pp. 179188, 2017.

[17] X. Wu, Y. Peng, J. Xu, Q. Yan, W. Nie, and T. Zhang, "Experimental study on evolution law for particle breakage during coal and gas outburst," International Journal of Coal Science \& Technology, vol. 7, no. 1, pp. 97-106, 2020.

[18] C. Xin, F. du, K. Wang, C. Xu, S. Huang, and J. Shen, "Damage evolution analysis and gas-solid coupling model for coal containing gas," Geomechanics and Geophysics for Geo-Energy and Geo-Resources, vol. 7, no. 1, p. 7, 2021.

[19] H. Xie, X. Zhao, J. Liu, R. Zhang, and D. Xue, "Influence of different mining layouts on the mechanical properties of coal," International Journal of Mining Science and Technology, vol. 22, no. 6, pp. 749-755, 2012.

[20] Y. Cheng, H. Liu, P. Guo, R. Pan, and L. Wang, "A theoretical model and evolution characteristic of mining-enhanced permeability in deeper gassy coal seam," Journal of China Coal Society, vol. 8, pp. 1650-1658, 2014.

[21] K. Wang and F. du, "Coal-gas compound dynamic disasters in China: a review," Process Safety and Environmental Protection, vol. 133, pp. 1-17, 2020.

[22] C. Wu, C. Yuan, G. Wen, L. Han, and H. Liu, "A dynamic evaluation technique for assessing gas output from coal seams during commingling production within a coalbed methane well: a case study from the Qinshui Basin," International Journal of Coal Science and Technology, vol. 7, no. 1, pp. 122-132, 2020. 